\title{
Elma meyvesinin fizikomekanik özelliklerinin robotik hasada etkisi
}

\author{
Erhan KAHYA ${ }^{1}$, Selçuk ARIN ${ }^{2}$ \\ ${ }^{1}$ Namık Kemal Üniversitesi Teknik Bilimler Meslek Yüksekokulu, Tekirdağ \\ ${ }^{2}$ Namık Kemal Üniversitesi Ziraat Fakültesi, Biyosistem Mühendisliği Bölümü, Tekirdağ \\ Alınış tarihi: 16 Nisan 2018, Kabul tarihi: 8 Mayıs 2019 \\ Sorumlu yazar: Erhan KAHYA, e-posta: ekahya@nku.edu.tr
}

\section{$\ddot{0} \mathbf{z}$}

$\mathrm{Bu}$ araștırmanın amacı elma meyvesinin fizikomekanik özelliklerinin robotik hasada etkisinin belirlenmesidir. Robotik sistemin kullanılmasında en önemli girdinin kameradan gelen koordinatlardır. Koordinatların belirlenmesinde yüzey alanı kullanılmıştır. Analizler sonucunda ölçülen değerler ile robotik hasadın arasında ilişki olduğu gözlenmiştir. Yüzey alanı ile yükseklik, genişlik, kalınlık ve küresellik değerlerinin robotik hasatta kullanılan görüntü işleme için önemli hasat değerleri olduğu anlaşılmıştır. Bu değerlerin yüzey alanı ile doğrudan ilişkisi olduğu saptanmıştır. Robotik hasat için yapılacak görüntü işlemede en önemli değerin yüzey alanı değeri olduğu yapılan ölçümlerde ve hesaplamalarda anlaşılmıştır. Meyvenin yerinin belirlenmesinde kullanılan yüzey alanının orta noktası değerinin her meyvede farklılık gösterdiği tespit edilmiștir.

Anahtar kelimeler: Elma, fizikomekanik, robotik hasat, görüntü işleme

The robotic impact of the physicomechanical properties of apple juice

\begin{abstract}
The purpose of this research is to determine the effect of the physicomechanical properties of on robotic harvest of apple fruit. The most important input for the use of the robotic system is the coordinates from the camera. The surface area is used when the coordinates are specified. It is observed that there is a correlation between measured values and robotic harvest. There is a significant relationship between surface area and height, width, thickness and sphericity values
\end{abstract}

according to measurements and calculations made. It is understood that these factors have a direct effect on the surface area of the fruit. It is understood that the more important value for image processing is the surface area. Since the coordinates are determined according to the midpoint, it has been determined that the $\mathrm{x}$ and $\mathrm{y}$ coordinates of each of the fruits are different.

Key words: Apple, physicomechanical, robotics harvest, cutting, image processing

\section{Giriş}

Dünyada tarım gittikçe sanayileşmektedir. Artık daha büyük tarım alanları, daha verimli olarak ișlenmekte, büyük șirketlerin elinde binlerce ișçinin çalıştığı fabrikalara dönüşmektedir. $\mathrm{Bu}$ dönüşme sürecinde işçilik maliyetleri artmaktadır. Maliyet artışı nedeniyle tüm sanayi kollarında olduğu gibi tarımda da robot kullanımı yaygınlaşmaya başlamıştır. İşçilik maliyetlerinin azaltılması, verimin arttırılması, hasadın kolaylaştırılması gibi hizmetlerde robot kullanımı artmaktadır. Mikrociplerin gelişmesine bağlı olarak robot yapım maliyetleri her geçen gün düşmektedir. Bu düşüşle beraber robot kullanımı her sanayi kolunda artmaktadır. Robot kullanımının artmasına paralel olarak dünya üzerinde birçok araştırma çalışmaları yapılmaktadır. Tarımda yapılan robotik çalıșmalara robotik domates, çilek, elma, portakal hasat makinaları örnek verilebilinir. Bu çalışmalar sadece hasat ile sınırlı değildir. Robotik sulama sistemleri, robotik haritalama sistemleri diğer uygulamalar için bir örnektir. Ülkemizde robotik sistemler daha çok hassas tarım uygulamalarında kullanılmaktadır. Bu uygulamalardaki temel amaç üretkenliği arttırmak için daha az tohum, gübre ve kimyasal ilaç tüketimi ile daha fazla ürün elde edilmesidir. Özellikle 
ülkemiz için önemli tarımsal ihracat değeri bulunan elma, domates, salatalık ve portakal gibi ürünler hasat aşamasından tüketiciye gelene kadar geçen sürede içinde kalitesinin en üst seviyede tutulması esas olmalıdır. İlk adım olan hasatta hassas tarım uygulaması ile bu sürecin başlatılması gerekmektedir. Bunun için hasattan başlayarak paketlenmesine kadar ürün değerinin kalitesinin korunması sağlanmalıdır. Önemli bir dış pazar girdisine sahip elma, gülgiller familyasının malus cinsinden olan ağaçlarının yenen meyvesi olarak bilinir. Elmanın anavatanı, Anadolu'yu da içine alan Güney Kafkas bölgesidir (Yıkar 2003). İnsanlık tarihinin ilk meyvesi sayılan elma, beslenme yönünden ve sağlık açısından çok yararlı bir meyvedir. Bileşimini \% 85 su ve \% 12 şekerdir. Ayrıca pektin, organik asitler, soda, fosfor, tanen, potasyum ile A,B1,B2,C,E vitaminlerini ihtiva etmektedir (Anonim 2002). Ülkemizde elma yetiştiriciliği tüm illerde yapılmakla birlikte özellikle son yıllarda belirli yörelerde yoğunlaşmış durumdadır. Ticari amaçla elma üretiminin gerçekleştirildiği işletmeler yeni teknik ve teknolojileri uygulayarak birim alandan daha çok ürün almayı çalıșmaktadırlar. 2010 verilerine göre Antalya, Isparta, Burdur illeri gurubu içinde elma üretiminde ilk sırada yer almakta ve Türkiye üretiminin \%30'unu karşllanmaktadır. Türkiye'de elma meyvesi hasadı daha çok elle yapılmakta olup henüz mekanizasyon uygulamaları elma hasat işlemlerine aktarılamamıştır. $\mathrm{Bu}$ nedenle hasat sırasında önemli kalite kayıpları oluşmakta ve önemli bir iş gücüne ihtiyaç duyurmaktadır. $\mathrm{Bu}$ konuda çalışmalar yürütülmekte olup, taranan literatürlerde robotik hasatla ilgili daha çok prototip çalışmalarına rastlanmıştır. Prototip çalışmalarından pratiğe aktarılan sistemler çok azdır. Robotik elma hasadıyla ilgili ilk çalışmalardan biri olan Kataoka ve ark.(2001) yapmış oldukları sistem ile robotik elma hasadı için elmaların yerinin tespitini ve otomatik algılama sistemini gerçekleştirmişlerdir. Çiftçiler hasat zamanının geldiğini elmanın rengine bakarak karar vermektedirler. Meyvenin renginin hasat zamanına karar vermek için en önemli kriter olduğunu belirtmişlerdir. Yapılan çalışmada hasat sezonundaki elma renkleri ve önceki elma renkleri Munsell renk sistemi temel alınarak, L*a * b* renk uzayı ve XYZ renk sistemine göre ayrılmıştır. Bu renk sistemine göre hasatın zamanı elma rengine göre bulunmuștur. Diğer bir çalışmada Bulanon ve ark. (2001), elma hasat robotu için gerçek zamanlı bir makine görme sisteminin geliştirilmesi üzerine bir araştırma yapmışlardır. Bu araştırmada kırmızı Fuji elması hasat robotu manipülatör rehberliği için gerçek zamanlı bir makine görme sistemi geliştirmişlerdir. CCD kamera yardımıyla elma bahçesinden görüntüler almışlardır. Elde edinilen görüntüler PC 'ye aktarılmış ve görüntü işleme yöntemiyle elmaların yerleri tespit edilmiştir. Farklı ışık koşullarında meyveleri tanımak ve yerlerinin tespitinin yapılması sağlanmıştır. Meyvenin tanımlanmasında kırmızı ve yeşil katsayıları kullanılmıștır. Araştırma sonucunda \%80'lik doğruluk ve \% 3'den az hata payı ile meyvenin tanımını yapmışlardır. Zhaoxiang ve ark.(2007), robotik elma hasadı için elmanın özelliklerinin ve pozisyonlarının belirlenmesi üzerine bir araştırma yapmışlardır. Sistem temel olarak multi-spectral görüntü tekniğinin ve trigometrik kadastro tekniğini kullanmaktadır. Sistemi oluşturmak için 2D görüntü sensorleri ve mikro işlemciler kullanmışlardır. 2D görüntü sensorleri yapısında iki adet laser ışın kullanılmıştır. Bunlardan ilki kırmızı laser demeti (685 nm.) diğeri infrared laser(830 nm.) demetidir. Laserler birbirlerine dik monte edilmiştir. Optik eksenleri birbirlerini keşişecek şekilde yapılmıştır. Meyvenin arkasinda konumlanmış bir ayna vasıtasıyla dönen ışınlar vasıtasıyla meyvenin konumunu belirlemişlerdir. Luo ve ark. (2018), robotik üzüm hasadı için kesme noktalarının belirlenmesi üzerine yaptıkları araștırmada üzüm kümelerinin yüzeysel kesişim noktalarını kullanmışlardır. Üzüm kümelerinin yerinin tespitinde piksel değerlerinin yüzey alanları ile ilişkisini temel almışlardır. Bir diğer çalışmada Redmond ve ark. (2018) robotik hasatta sebzeler için V-REP, ROS ve Matlab programları için simülasyon programı uygulaması yapmışlardır. Bu uygulamada giren değer için yüzey alan değerlerini kullanmışlardır. Tejanda ve ark. (2017) yılında yaptıkları bezelye hasadı için robotik uygulamada bezelyenin yerinin belirlenmesinde görüntü işlemeyi kullanmışlardır. Bu çalışmada da yüzey alanı temel değer olarak alınmıştır.

$\mathrm{Bu}$ araștırma elma meyvesinin hasat sırasında oluşabilecek zararlarının azaltılması, hasat süresinin kısaltılması amacıyla hasat için robot kolun geliştirilmesi amacıyla planlanmıştır. Görüntü işleme tekniği kullanılarak meyvenin yerinin tespiti, hasatta robot kol kullanımı amaçlanmıştır. Bu sayede daha hızlı bir şekilde insan gücüne bağlı kalmadan hasadın gerçekleştirilmesi istenmiştir. Yapılan çalışmalarda ortak nokta meyvelerin fizikomekanik 
özelliklerinin belirlenmesi ve belirlenen özelliklere göre robotik hasadın yapılmasıdır. Yaptığımız araştırmanın amacı, daha az sürede daha az zararla meyvenin hasadının yapılma tekniğinin geliştirilmesidir. Elma meyvesinin robotik hasadında ortaya çıkacak sorunların belirlenmesi, çözüm yollarının tespit edilmesi ve hangi fizikomekanik özelliklerin robotik hasada etkili olduğunun belirlenmesi amaçlanmıştır. Çalışmada, elma meyvesinin hasadında görüntü işleme tekniği ve robotik sistem üzerinde durularak, hasat sırasında robotik sistemin karşılaşacağ belirlenmiştir. Görüntü işleme ve robotik sistem ikilisinin kalibrasyonun önemi vurgulamıştır. Hangi fizikomekanik özelliklerin robotik hasada etkilediği yapılan ölçümlerle gösterilmiştir.

\section{Materyal ve Yöntemler}

\section{Materyal}

Yapılan çalışmada Şekil 1 'deki robotik sistem kurulmuştur. Robotik sistemin parçalar;

1.2D görüntü işleme sensörü

2.Robotik kol

3.Pnömatik kesici

4.Ultrasonik ses sensör.

5.Robotik Kontrol Kartı

6.Pnömatik Sistem Kontrolü

7.Meyve (Elma)

\section{D görüntü işleme sensörü}

Görüntü yakalama ve analiz görevlerini bir gövdenin içine entegre edilmiş, 640x380 piksel siyah beyaz sensörlü kameradır. Kamera içinde bulunan harici bellek ile yapılan programlar hafızada tutulmakta ve bilgisayardan bağımsız çalışmaktadır. İletişim portu 10/100 Mb 'Fast Ethernet'dir. Bu port ile TCP/IP ve UDP/IP protokolları ile bilgisayarla haberleșme yapabilmektedir. Ayrıca RS-285 seri iletişim port (çıkış) a sahiptir.Kontrolü kendisine ait yazılım ile yapılmaktadır.

\section{Robotik kol}

4 serbestlik dereceli (DOF) bir robot koldur. 4 eksenin robotun hareketini sağlamak için 3 adet SpringRC SM-8166B, 2 adet Savöx SV-0236 MG modeli servo motorlar kullanılmıştır. Kol uzunlukları $\mathrm{L}_{1}=20 \mathrm{~cm}, \mathrm{~L}_{2}=17 \mathrm{~cm}, \mathrm{~L}_{3}=15 \mathrm{~cm}$ 'dir. Robot kolun parçaları Şekil 2'de gösterilmiştir.

\section{Pnömatik kesici}

Paralel tutucu üzerine monte edilmiş makas sisteminden oluşmaktadır. Kontrolü pnömatik sistem ile yapılmıştır. Şekil 3'te pnömatik makas sistemi gösterilmiștir.

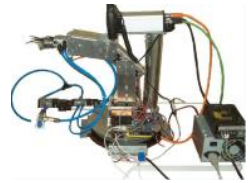

Şekil 2.Robot kol tasarımı(orjinal)

\section{Ultrasonik ses sensör}

Robotik kolun ileri ve geri hareketinin kontrol edilmesini sağlayan 'Parallax Ping' Ultrasonik sensör kullanılmıştır. $\mathrm{Bu}$ sensör ile uzay koordinat eksenindeki z ekseni kontrol edilmiştir.

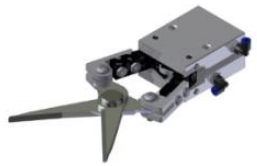

Șekil 3. Pnömatik makas sistemi

\section{Robotik kontrol kartı}

Robot ile görüntü ișleme arasında kontrolün sağlanmasın için 'Arduino Uno' kullanılmıștır. ATmega 328 tabanlı bir mikroişlemci geliştirme kartıdır ve 14 adet dijital giriş/çıkış bağlantısına,6 analog girişe, $16 \mathrm{Mhz}$ kristal osilatöre, USB bağlantısına, güç bağlantısına, ICSP bağlantısına ve reset tuşuna sahiptir.

\section{Pnömatik sistem kontrolü}

Pnömatik sistemin kontrolü için 2 adet Solenoid Valf MVSO-180-4E1 kullanılmıştır.

\section{Meyve (Elma)}

Denemeler elma meyvesi kullanılmış olup, meyveler ekim ayında, meyve ortalama boyutları uzunluk 47,98 mm. , genişliği 47,10 mm.,kalınlığı 47,50 mm. ve ağırlığı 53,77 gr'dır. Denemeler 100 adet 'Golden Delicious' çeşidine ait elma meyvesi ile yapılmıştır.

\section{Yöntem}

\section{Meyvenin fizikomekanik özelliklerinin belirlenmesi}

Denemeler için kullanılacak elma meyveleri, ağaçtaki dallar üzerinden 100 adet tesadüfen seçilmiştir. Meyvelerin ölçümleri $0.01 \mathrm{~mm}$ hassasiyetli 0-150 mm arasında ölçüm yapabilen dijital kumpas kullanılarak yapılmıştır. Sistemde kullanılan kameranın iki boyutlu görüntü işlemesinden dolayı görüntü işleme için gerekli olan meyvenin geometrik ortalama çap ve küresellik değerlerinin belirlenmesinde aşağıdaki eşitlikler kullanılmıştır . (Mohsenin, 1980).

$$
\mathrm{Dg}=\left(\mathrm{LD}^{2}\right)^{1 / 3}
$$


Eşitlikte; Dg = geometrik ortalama çap $(\mathrm{mm}), \mathrm{L}$ : uzunluk (mm) ve D:ürün çapı (mm)'dır.

Küresellik değeri geometrik ortalama çap değerine bağlı olarak hesaplanmıştır (Mohsenin 1980)

$$
\Phi=\frac{\mathrm{Dg}}{\mathrm{L}}
$$

Eşitlikte; $\Phi$ : küresellik katsayısı, Dg: geometrik ortalama çap (mm) ve L: uzunluk (mm)'tur.

Elmanin yüzey alanı ise aşağıda verilen eșitlik yardımı ile hesaplanmıștır (Mohsenin, 1980).

$$
\mathrm{S}=\pi \mathrm{Dg}^{2}
$$

Eşitlikte; S: yüzey alanı $\left(\mathrm{mm}^{2}\right), \mathrm{Dg}$ : geometrik ortalama çap (mm)'tır.

Örneklerin hacmi, ölçekli bir kapta hacim değiștirme esasına göre belirlenmiştir. Meyve kopma kuvveti daldan kopma anında dinamometrede okunan değer belirlenmiştir.

\section{Meyvenin koordinatlarının bulması ve kesme durumları}

Deneme sirasında 100 adet elma ve elma meyvesi dalıyla beraber rastgele yerleşim uygulanarak kurulan düzeneğe yerleştirilmiştir. Robotik sistem ile meyve hasadı yapılabilmesi için gerekli olan en önemli değişken meyvelerin uzay koordinat eksenlerinin hesaplanıp belirlenmesidir. Denemeler için kurulan sistemde kameranın yeri robot kolun maksimum uzanma mesafesine ve kameranın maksimum görüş alanı olan 640 x $380 \mathrm{~mm}$ göre yerleştirilmiştir. Meyvenin yerden maksimum yüksekliği 28.5 cm'dir. Meyvenin robot kolun merkezinde uzaklığı $28 \mathrm{~cm}$ olarak ayarlanmıştır. Meyvenin robot kolun merkezine olan uzaklık $28 \mathrm{~cm}$ ayarlanmasından dolayı kameranın görüş alanı ölçütü 170 x 130 mm olmuştur. Şekil 4'de Kameranın ayar durum uzaklığ gösterilmiştir. Maksimum uzanma mesafesi ile dal üzerinde bulunan meyvenin sapına makasın konumlandırılması sağlanmıștır. Koordinat eksenlerinin bulunması için görüntü işleme tekniği uygulanmıştır.

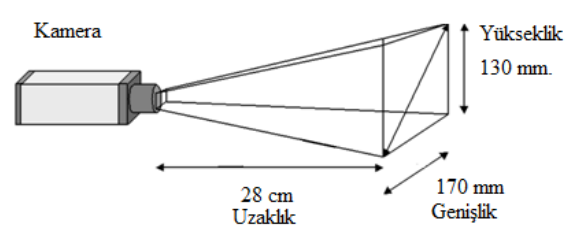

Şekil 4. Kamera ayar durum uzaklığı
Meyvenin dal üzerinde yerinin tespiti için 2D kamera ve ultrasonik sensör kullanılmıştır. $\mathrm{Bu}$ kamera yardımıyla dijital ortama aktarılan görüntüler görüntü işleme için C\# dilinde yazılan program yardımıyla işlenmiştir. Aktarılan görüntü içinde meyvenin dal üzerindeki yerinin dijital ortamda bulunması sağlanmıştır. $\mathrm{Bu}$ işlem için meyvenin özgün şeklinin sisteme tanıtılması yazılan program vasıtasıyla yapılmıştır. Şekil analizi ile meyvelerin uzay koordinat eksenindeki yatay ekseni ( $\mathrm{x}$ ) ve dikey ekseni (y) değerleri bulunmuştur. Robot kolun ileri hareketi için gerekli ola z eksen hareketi ultrasonik sensör yardımıyla yapılmıștır. Bu sensörün kullanımı için C\# dilinde kod yazılmış, robot kolun meyveye 10 cm yaklaştığında ileri gitmesi önlenmiştir. Robotik Kontrol kartındaki işlemciye kameradan gelen koordinata göre yapılan hesaplamalardan sonra robot kolun hareketi sağlanmıștır. Pnömatik makasın kontrol edilmesi robotik kontrol kartı ile yapılmış ve yazılan program ile servonun dönüşü sağlanmıştır. Pnömatik sistem 5 ile 8 bar arasında basınç veren kompresöre $8 \mathrm{~mm}$. çapında hortumlarla bağlanmıștır. Sistemin kontrolü yazılan program vasıtasıyla kontrol valflerinin çalıştırılması şeklinde yapılmıştır. Kontrol valfleri yardımıyla 5 ile 8 bar arasındaki basınç altında makasın açılıp kapanması sağlanmıştır. Şekil 5'de kesme durumu gösterilmiştir.

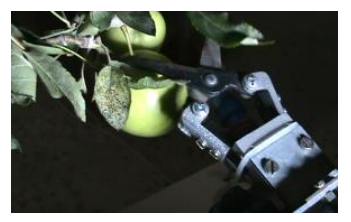

Şekil 5.Meyvenin kesme durumu

\section{Bulgular ve Tartışma}

\section{Fizikomekanik özellikleri}

Hesaplanan değerlere göre elma meyvesinin fizikomekanik özelliklerine ait değerleri Çizelge 1'de verilmiştir.

Çizelge 1. Fizikomekanik istatistiği

\begin{tabular}{lcccc}
\hline & Min. & Mak. & Ort. & Std. Sap. \\
\hline Meyve kopma kuv.(kg) & 0,17 & 0,47 & 1,4762 & 4,62168 \\
Yükseklik(mm) & 40,87 & 56,42 & 47,9880 & 3,34668 \\
Genişlik(mm) & 40,11 & 59,20 & 47,1090 & 3,47855 \\
Kalınlık(mm) & 40,11 & 54,23 & 47,5055 & 3,38887 \\
Ağırlık(g) & 39,00 & 79,94 & 53,7755 & 10,18564 \\
Küresellik(\%) & 0,88 & 1,07 & 0,9885 & 0,04172 \\
Yüzey alanı(cm $\left.{ }^{2}\right)$ & 53,51 & 95,32 & 70,7117 & 9,27779 \\
Hacim(cm $\left.{ }^{3}\right)$ & 30,00 & 80,00 & 55,1500 & 10,03668 \\
Sap kalınlığı(mm) & 1,05 & 2,07 & 1,6026 & 0,25397 \\
\hline
\end{tabular}


Araştırma sonucunda elde edilen veriler istatistiksel olarak değerlendirilmiş ve korelasyon analizi yapılmıştır. Korelasyon analizine ilişkin bulgular Çizelge 2'de verilmiştir. Çizelge 2'deki elma için yapılan korelasyon analizi sonuçları sonuçlarına göre;

1-Meyve kopma kuvveti ile meyve ağırlığı ve diğer özellikler arasında ilişki bulunmamıştır.

2-Meyve uzunluğu ile meyve kopma kuvveti ve sap kalınlığı arasındaki ilişki önemsiz, genişlik, kalınlık, ağırlık, yüzey alanı, hacim arasındaki ilişki istatistiksel $\mathrm{P}<0,05$ değerine göre önemli olduğu görülmüştür.

3-Meyve genişliği ile meyve kopma kuvveti ve sap kalınlığı arasındaki ilişki önemsiz, yükseklik, ağırlık küresellik, kalınlık, yüzey alanı, hacim arasındaki ilişki istatistiksel $\mathrm{P}<0,05$ değerine göre önemli olduğu görülmüştür.

4-Meyve kalınlığı ile meyve kopma kuvveti, küresellik, yüzey alanı ve sap kalınlığı arasındaki ilişki önemsiz, yükseklik, genişlik, ağırlık ve hacim arasındaki ilişki istatistiksel $\mathrm{P}<0,05$ değerine göre önemli olduğu görülmüştür.

5-Meyve ağırlığı ile meyve kopma kuvveti, küresellik ve sap kalınlığı arasındaki ilişki istatistiksel olarak önemsiz, yükseklik, genişlik, kalınlık, yüzey alanı ve hacim arasındaki ilişki istatistiksel $\mathrm{P}<0,05$ değerine göre önemli olduğu görülmüştür.

6-Meyve küreselliği ile yükseklik ve genişlik arasındaki ilişki istatistiksel $\mathrm{P}<0,05$ değerine göre önemli olduğu görülmüștür.
7-Meyve küreselliği ve meyve kopma kuvveti, kalınlık, ağırlık, yüzey alanı, hacim ve sap kalınlığı arasındaki ilişki önemsizdir.

8-Meyve yüzey alanı ile meyve toplama kuvveti, kalınlık, küresellik, sap kalınlığı arasındaki ilișki istatistiksel olarak önemsiz, yükseklik, genişlik, ağırlık ve hacim arasındaki ilişki istatistiksel $\mathrm{P}<0,05$ değerine göre önemli olduğu görülmüştür.

9-Meyvenin hacmi ile meyve kopma kuvveti, küresellik, sap kalınlığı arasındaki ilişki istatistiksel olarak önemsiz, yükseklik, genişlik, kalınlık, ağırlık ve yüzey alanı arasındaki ilişki istatistiksel $\mathrm{P}<0,05$ değerine göre önemli olduğu görülmüştür.

10-Sap kalınlığı ile meyve kopma kuvveti ve diğer özellikler arasında ilişki bulunmamıştır.

Robotik elma hasadı için gerekli olan koordinat değerlerinin meyvenin küresellik ve yüzey alan değerleriyle ilişkili olduğu görülmüştür. Benzer çalışmalardan biri olan Feng ve ark(2019) yılında yapmış oldukları çalışmada elmanın renk ve şekil faktörlerini kullanarak robotik hasat makinası yapmışlardır. Diğer bir çalışmada Zhao ve ark (2011) yılında yapmış oldukları çalışmada görüntü işlemede elmanın şekilsel özelliklerin kullanmışlardır. Beaten ve ark. (2009) , yılında yapmış oldukları çalışmada ise robotik elma hasadı için Özerk Meyve Toplama Makinesinin (AFPM) yapısı ve işlevselliği üzerine robotik makine geliştirmişlerdir. $\mathrm{Bu}$ çalışmada oluşturulan sistemde kıskaç, içine kamera ve silikon huni yer almaktadır. Görüntü işlemede meyvenin şekilse özelliğini kullanmışlardır.

Çizelge 2. Elma için korelasyon değerleri

\begin{tabular}{|c|c|c|c|c|c|c|c|c|c|}
\hline & $\begin{array}{c}\text { Meyve } \\
\text { kopma } \\
\text { kuv. (kg) }\end{array}$ & $\begin{array}{l}\text { Yükseklik } \\
\text { (mm) }\end{array}$ & $\begin{array}{l}\text { Genişlik } \\
\text { (mm) }\end{array}$ & $\begin{array}{l}\text { Kalınlık } \\
\text { (mm) }\end{array}$ & $\begin{array}{l}\text { Ağırlık } \\
\text { (gr) }\end{array}$ & $\begin{array}{c}\text { Küresellik } \\
(\%)\end{array}$ & $\begin{array}{l}\text { Yüzey } \\
\text { alanı } \\
\left(\mathrm{cm}^{2}\right)\end{array}$ & $\begin{array}{l}\text { Hacim } \\
\left(\mathrm{cm}^{3}\right)\end{array}$ & $\begin{array}{c}\text { Sap } \\
\text { kalınlığ } \\
(\mathrm{mm})\end{array}$ \\
\hline Meyve kopma kuv. & & -.004 & -.119 & -.111 & -.165 & -.127 & -.087 & -.014 & .042 \\
\hline Yükseklik & -.004 & & .618 & .548 & .456 & -.394 & .812 & .336 & .047 \\
\hline Genişlik & -.119 & .618 & & .690 & .485 & .476 & .959 & .473 & -.003 \\
\hline Kalınlık & -.111 & .548 & .690 & & .469 & .199 & .297 & .423 & .147 \\
\hline Ağırlık & -.165 & .456 & .485 & .469 & & .065 & .514 & .351 & .025 \\
\hline Küresellik & -.127 & -.394 & .476 & .199 & .065 & & .211 & -.069 & -.040 \\
\hline Yüzey alanı & -.087 & .812 & .959 & .297 & .514 & .211 & & .308 & .014 \\
\hline Hacim & -.014 & .336 & .473 & .423 & .351 & -.069 & .308 & & -.028 \\
\hline Sap kalınlığı & .042 & .047 & -.003 & .147 & .025 & -.040 & .014 & -.028 & \\
\hline
\end{tabular}

$(\mathrm{P}<0.05 ; \mathrm{n}=100)$

\section{Meyvenin yerinin tespit özellikleri}

Elma için robot kolun meyveyi bulma oranı \%85, olarak yapılan analiz sonunda tespit edilmiştir. Bunlara ait istatistik değerleri Çizelge 3'de, Çizelge 4'de $\mathrm{x}$ ve $\mathrm{y}$ koordinatlarına göre başarı oranları verilmiştir. Bağımsız $\mathrm{x}$ ve $\mathrm{y}$ koordinat eksen değerlerinin ortalamalarının robot kolun hareketi için gerekli olan bağımlı değişken değerinden hangisini etkilediği analiz edildi. $\mathrm{Bu}$ analize göre bulma değerlerine yapılan t-testinde $\mathrm{x}$ koordinatı değerinin robot kolun meyvenin yerini bulunması için önemli olduğu görülmüştür. Robot kolun 
meyveye konumlanmasından sonra meyveyi kesme değerleri için durum değerlerine ait bilgiler istatistiksel olarak analiz edilmiş ve sonuçlar elma için Çizelge 5'te gösterilmiştir. Elma için robot kolun meyveyi kesme oranı \%73 olarak yapılan analiz sonunda tespit edilmiştir. Bağımsız t-testi için koordinatların kesme üzerindeki etkilerinin analizi yapılmıştır. Çizelge 6 'da elma için bulunan analiz değerleri özetlenmiştir.
Çizelge 3. Bulma değerleri için ortalama ve standart sapma değerleri

\begin{tabular}{lccccc}
\hline Bulma evet & & Adet & Ort & Std. Sap. & Std. Hata Or. \\
\hline Kamkoordx & $1.00^{*}$ & 85 & 284.197 & 117.105 & 13.019 \\
$* *$ & $.00^{*}$ & 15 & 533.411 & 35.657 & 7.268 \\
\hline $\begin{array}{c}\text { Kamkoordy } \\
* *\end{array}$ & $1.00^{*}$ & 85 & 331.988 & 41.872 & 1.483 \\
\hline 0=Hayr, 1=Evet; & **Kamkoordx=x & kamera & koordinatl, \\
Kamkoordy=y kamera koordinatı & &
\end{tabular}

Çizelge 4. Kameranın x ve y koordinatlarına göre bulma yüzdeleri (T.testi)

\begin{tabular}{|c|c|c|c|c|c|c|c|c|c|c|}
\hline & & \multicolumn{2}{|c|}{$\begin{array}{l}\text { Levene's Test için } \\
\text { varyans eșitliği }\end{array}$} & \multicolumn{7}{|c|}{ t-test için Ortalama Eşitliği } \\
\hline & & $\mathrm{F}$ & Sig. & $\mathrm{t}$ & df & Sig. & $\begin{array}{c}\text { Ortala } \\
\text { ma } \\
\text { Farklılı } \\
\text { k }\end{array}$ & $\begin{array}{c}\text { Std. } \\
\text { Hata } \\
\text { Ayrımı }\end{array}$ & $\begin{array}{c}\text { \% } 95 \\
\text { Güven } \\
\text { aralığı } \\
\text { Üst }\end{array}$ & $\begin{array}{c}\text { \% } 95 \\
\text { Güven } \\
\text { aralığı } \\
\text { Alt }\end{array}$ \\
\hline \multirow{2}{*}{$\begin{array}{c}\text { Kamkoord } \\
x^{*}\end{array}$} & $\begin{array}{l}\text { Varsayıla } \\
\text { n Eşit } \\
\text { Varyansl } \\
\text { ar }\end{array}$ & 15,485 & 0,000 & $-8,145$ & 98 & 0,000 & $\begin{array}{c}- \\
249,21\end{array}$ & 30,596 & $-309,933$ & $-188,496$ \\
\hline & $\begin{array}{c}\text { Varsayıla } \\
\text { n Eşit } \\
\text { olmayan } \\
\text { Varyansl } \\
\text { ar } \\
\end{array}$ & & & $\begin{array}{c}- \\
15,886\end{array}$ & 73,58 & 0,000 & $\begin{array}{c}- \\
249,21\end{array}$ & 15,687 & $-280,475$ & $-217,953$ \\
\hline \multirow[b]{2}{*}{$\begin{array}{c}\text { Kamkoord } \\
y^{*}\end{array}$} & $\begin{array}{l}\text { Varsayıla } \\
\text { n Eşit } \\
\text { Varyansl } \\
\text { ar }\end{array}$ & 2,387 & 0,126 & $-2,125$ & 98 & 0,036 & $-24,15$ & 11,367 & $-46,711$ & $-1,594$ \\
\hline & $\begin{array}{c}\text { Varsayıla } \\
\text { n Eşit } \\
\text { olmayan } \\
\text { Varyansl } \\
\text { ar }\end{array}$ & & & $-2,573$ & 23,49 & 0,017 & $-24,15$ & 9,3886 & $-43,551$ & $-4,753$ \\
\hline
\end{tabular}

*Kamkoordx=x kamera koordinatı , Kamkoordy=y kamera koordinatı

Çizelge 5. Elma için robotik kesme durumu

\begin{tabular}{cccccc}
\hline Bulma evet & & Adet & Ort & Std. Sap. & Std. Hata Or. \\
\hline $\begin{array}{c}\text { Kamkoordx } \\
* *\end{array}$ & $1.00^{*}$ & 73 & 265.121 & 111.364 & 14.512 \\
& $0.00^{*}$ & 27 & 474.225 & 89.197 & 16.686 \\
\hline $\begin{array}{c}\text { Kamkoordy } \\
* *\end{array}$ & $1.00^{*}$ & 73 & 328.275 & 42.796 & 1.120 \\
& $0.00^{*}$ & 27 & 355.445 & 29.400 & 5.078 \\
\hline
\end{tabular}

*0=Hayır, $\quad 1=$ Evet; $\quad{ }^{* *}$ Kamkoordx $=\mathrm{x} \quad$ kamera koordinat, Kamkoordy=y kamera koordinatı

1 (evet), 0 (hayır) olarak meyvenin analiz değeri analiz edilmiştir. Yapılan denemeler sonucunda elma için kesme başarı oranı \%73 olarak bulunmuştur. Robotik sistemin hareketini sağlayan yatay (x), dikey (y) eksen değerleri yapılan t-testi sonucuna göre elma için yatay eksenin (x) anlamlı olduğu görülmüștür. Robotik sistemin görüntü işleme ile birlikte doğru hareket etmesi için gerekli eksen değerinin yatay eksen ( $\mathrm{x}$ ) olduğu anlaşılmıștır.

Denemeler sonunda, elma için \%27'lik robotik hareketin yanlış konumlanma yaptığı tespit edilmiştir. Gözlemler sonucunda meyvelerin dal üzerinde yan yana veya arka arkaya durmasından dolayı kameranın görüntüyü yanlış seçmesine neden olduğu anlaşıllmıştır. İlk gördüğü şeklin tam olan meyve değil tanitılan ş̧ekle en uygun meyvenin koordinatlarının verildiği tespit edilmiștir.

\section{Sonuç ve Öneriler}

Yapılan araştırma sonucunda robotik meyve hasadı için kullanılan görüntü işlemede meyvenin fizikomekanik özelliklerinin doğrudan etkisi olduğu gözlenmiştir. $\mathrm{Bu}$ değerlerden ağırlık, uzunluk, genişlik, kalınlık değerlerinin yüzey alanına etkisi incelenmiștir. Yapılan denemeler sonucunda \% 85 bulma oranı elde edilmiştir. Robot kolun hareketini sağlayan yatay (x) , dikey (y) eksen değerleri yapılan $\mathrm{T}$-testi sonucuna göre elma için yatay eksenin $(\mathrm{x})$ anlamlı olduğu görülmüştür. Robot kolun görüntü işleme ile birlikte doğru hareket etmesi için gerekli eksenin yatay eksen (x) olduğu anlaşılmıştır. Meyvenin bulunan koordinatlara göre kopartılma başarı oranı \%73 olarak yapılan istatistiksel 
sonuçlarda görülmüştür. Bulma ile kesme arasındaki farklılık nedeni meyvenin makas üzerindeki konumu olduğu görülmüştür. Yapılan T-testi sonucunda meyvenin dal üzerinde kopartılması için sadece $\mathrm{x}$ ekseni değil ayrıca y ekseninin de önemli olduğu tespit edilmiştir. Makasın konumlanması sırasında y eksen değeri makasın meyvenin sapına konumlanmasını sağladığı görülmüştür. Meyve sapının makasın ucunda olması, makasın meyvenin sapına değil meyve yumrusuna gelmesi, meyve ile meyve sapı başlangıç noktasına gelmesi ve saptaki budağa gelmesi koparma işlemi için hata oluşmasına neden olduğu görülmüştür. Bunun önlenmesi için meyvenin makas ucundan içeri doğru çekilmesi ve sabit tutulması ile kesme işlemindeki başarının artacağl görüșüne varılmıştır. Meyvenin içeriye çekilmesi için kullanılan vakum jeneratörü ucundaki vakum pedinin her meyve için özel dizayn yapılması meyvenin sabit tutulması başarısını arttıracağ düşünülmektedir. Meyvenin yerinin tespiti için sadece geometrik ortalama çap ve küresellik değerlerinin yeterli olduğu anlaşılmıștır. Sap kalınlığının kesme kuvvetinin belirlenmesine etkili olduğu yapılan denemelerde görülmüştür. Meyvenin saptan kopartılması için güçlü kesim yapacak pnömatik makas sisteminin kullanılması gerektiği anlaşılmıştır. Meyvenin robotik hasat ile dal üzerinden kopartılmasında kullanılacak gripper dizaynının meyvenin fizikomekanik özelliklerine göre tasarlanması gerektiği anlaşılmıştır Araştırmada kullanılan gripper dizaynının ve görüntü işleme tekniğinin uygun olduğu görülmüștür.

Çizelge 6. Elma için kesme T-testi

\begin{tabular}{|c|c|c|c|c|c|c|c|c|c|c|}
\hline & & $\begin{array}{l}\text { Levene's } \\
\text { için }\end{array}$ & $\begin{array}{r}\text { Test } \\
\text { varyans }\end{array}$ & \multicolumn{7}{|c|}{ t-test için Ortalama Eşitliği } \\
\hline & & $\mathrm{F}$ & Sig. & $\mathrm{t}$ & df & Sig. & $\begin{array}{c}\text { Ortalama } \\
\text { Farklılık }\end{array}$ & $\begin{array}{c}\text { Std. } \\
\text { Hata } \\
\text { Ayrımı }\end{array}$ & $\begin{array}{c}\text { \% } 95 \\
\text { Güven } \\
\text { aralığı } \\
\text { Üst }\end{array}$ & $\begin{array}{c}\text { \% } 95 \text { Güven } \\
\text { aralığ } \\
\text { Alt }\end{array}$ \\
\hline \multirow[b]{2}{*}{ Kamkoordx* } & $\begin{array}{c}\text { Varsayılan } \\
\text { Eşit } \\
\text { Varyanslar }\end{array}$ & 3.938 & .049 & -8.763 & 98 & 0.000 & -209.103 & 23.861 & -256.456 & -161.750 \\
\hline & $\begin{array}{c}\text { Varsayılan } \\
\text { Eşit } \\
\text { olmayan } \\
\text { Varyanslar }\end{array}$ & & & -9.701 & 57.697 & 0.000 & -209.103 & 21.553 & -252.253 & -165.954 \\
\hline \multirow[b]{2}{*}{ Kamkoordy* } & $\begin{array}{c}\text { Varsayılan } \\
\text { Eşit } \\
\text { Varyanslar }\end{array}$ & 7.064 & .009 & -3.039 & 98 & 0.003 & -27.169 & 8.939 & -44.909 & -9.430 \\
\hline & $\begin{array}{c}\text { Varsayllan } \\
\text { Eşit } \\
\text { olmayan } \\
\text { Varyanslar }\end{array}$ & & & -3.595 & 67.707 & 0.001 & -27.169 & 7.556 & -42.250 & -12.089 \\
\hline
\end{tabular}

*Kamkoordx=x kamera koordinatı, Kamkoordy=y kamera koordinatı

Teşekkür

$\mathrm{Bu}$ araştırma Namık Kemal Üniversitesi BAP tarafından desteklenmiştir. Proje No: NKÜBAP.00.24.DR.10.05

\section{Kaynaklar}

Anonim, 2002. Tarımda elmanın yeri, ito.org.tr/Dokuman/Sektor/1-32.pdf (erişim tarihi,16.10.2012).

Baeten, J., Donn'e, K., Boedrij, S., Beckers, W., Claesen, E., 2007. Autonomous fruit picking machine: a robotic apple harvester, $6^{\text {th }}$ International Conference on Field and Service Robotics FSR 2007, Jul 2007, Chamonix, France.
Bulanon, D.M., Kataoka, T., Ota, Y., Hiroma, T., 2001. Estimation of apple fruit location using machinehine vision system for apple harvesting robot. Internatioan Commision of Agricultural and Biosysmes Engineering the CIGR Journal of Scientific Research and Development, 3: ,1-6.

De-An, Z.Jjidong, L.,Wei, J.,Ying, Z.,Yu, C., 2011. Design and control of an apple harvesting robot. Biosystema Engineering, 10: 112-122.

Feng, J., Zeng, L., He, L., 2019. Apple fruit recognition algorithm based on multi-spectral dynamic image analysis, Sensors 19: 949-950.

Lufeng, L., Yunchao, T.,Qinghu,a L., Xiong, C.,Po, Z., Xiangjun, Z., 2018. A vision methodology for harvesting robot to detect cutting points on 
peduncles of double overlapping grape clusters in a vineyard, Computers in Industry, 99: 130-139

Kataoka, T., Okamoto, H., Hata, S., 2001. Automatic detecting system of apple harvest season for robotic apple harvesting. 2001 ASAE Annual International Meeting. Sacramento Convention Center Sacramento, 01-3132, California, USA.

Mohsenin, N.N., 1980. Physical properties of plant and animal material. New York: Gordon and Breach.

Redmond, R.S., Ibrahim, A.H., Manoj, K., Cornelia, W., 2018. Robotic harvesting of fruiting vegetables: a simulation approach in V-REP, ROS and MATLAB, Automation in Agriculture - Securing Food Supplies for Future Generations, Publisher: In Tech Open,Page: 81-105.
Tejada, V.F., Stoelen, M.F. , Kusnierek, K. , Heiberg, N, Korsaeth, A. 2017. Proof-of-concept robot platform for exploring automated harvesting of sugar snap peas, Precision Agriculture, An International Journal on Advances in Precision Agriculture, 18(6): 952-972

Yıkar, E., 2003. Elma, Tarımsal Ekonomi Araştırma Enstitüsü, Sayı 4, Nüsha 7, ISSN 1303-8346, Ankara (erişim tarihi,16.10.2012).

Zhaoxiang, L., Gang, L., 2007. Apple maturity discrimination and positioning system in an apple harvesting robot. New Zealand Journal of Agricultural Research, 103-1113. 